\title{
CORRECTION
}

\section{Correction to: A native Trichoderma harzianum strain Th62 displays antagonistic activities against phytopathogenic fungi and promotes the growth of Celosia cristata}

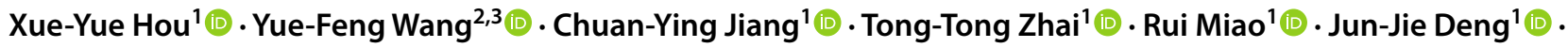 \\ Zhi-Hong Yao ${ }^{1}$ (D) Rong-Shu Zhang ${ }^{1}$ (i)
}

Published online: 25 November 2021

(c) Korean Society for Horticultural Science 2021

\section{Correction to: \\ Horticulture, Environment, and Biotechnology (2021) 62:169-179 \\ https://doi.org/10.1007/s13580-020-00307-w}

In this article, the order that the authors appeared in the author list and the affiliations of Yue-Feng Wang were incorrect. The corrected author list is given above. The original article has been corrected.

Publisher's Note Springer Nature remains neutral with regard to jurisdictional claims in published maps and institutional affiliations.

The original article can be found online at https://doi.org/10.1007/ s13580-020-00307-w.

Rong-Shu Zhang

zrs6504@nefu.edu.cn

1 College of Landscape Architecture, Northeast Forestry University, Harbin, China

2 Photosynthesis Research Center, CAS Key Laboratory of Photobiology, Institute of Botany, Chinese Academy of Sciences, Beijing 100093, China

3 University of Chinese Academy of Sciences, Beijing 100049, China 